\title{
Efficacy and Utilization of Unmanned Aerial System (Uas) as Operational Tools for Disaster Management in India
}

${ }^{1}$ Kunal Sharma, ${ }^{2}$ Brig Ajay Gangwar, ${ }^{3}$ Col Rahul Devrani, ${ }^{4}$ Raja Chakraborty

National Disaster Management Authority

\begin{abstract}
$\underline{\text { ABSTRACT }}$
The disaster response operational strategies requires tool that a may provide time bound clear picture of potential spots. Natural disaster sometimes comes slowly like increment of water level resulting flood or early warning of tsunami whereas in manmade disasters like ${ }^{1} \mathrm{CBRNE}$ attack or chemical accident or industrial structure collapse or leakage through a pipeline of some toxic hazardous gas requires very accurate and quick response strategies. ${ }^{2}$ Unmanned Aerial System is commercially used tools present in the market and also used by military organization for various operations throughout the world. The accuracy and time bound pictorial representation of the spots by these tow tools makes them very useful for providing clear picture of potential disaster sites and enabling decision makers to take decision on these representation. Apart of these the potential to deliver important material faster than any other mode also makes these equipment and technology a very important asset for making disaster risk reduction strategies. This paper elaborates the efficacy and utility of Unmanned Aerial System or Drones in developing robust and time bound strategies for disaster risk reduction. This paper also evaluates some experiences and describes some initiatives using Unmanned Aerial System to support disaster risk reduction strategies and post disaster decision making efforts.
\end{abstract}

\section{KEYWORDS}

Disaster, Operational Strategies, UAV, Drones, Man Made \& Natural Disaster, CBRNE

\section{$\underline{\text { INTRODUCTION }}$}

The tools requirement for operation ${ }^{3}$ disaster risk reduction strategies should be very fast and accurate. Time bound practices is the first requirement for handling situation and formulating strategies in disasters. The purpose for formulating time bound ${ }^{4}$ disaster management response strategy will very well achieved by using Unmanned Aerial System or Drone in emergency situation. An operational and tactical UAV application in disaster management using a time-scaled separation of the application, like pre \& post disaster situation handling and the activity after the primary disaster elimination will be beneficial for decision makers for formulating strategies.

In the 21st Century, application of UAS in all facets of disasters management is one of the important technological uses in areas such as landslide, earthquake, flood, damage assessment, relief etc. This technology is in demand due to compatibility of fast mapping with high resolution real time images of inaccessible areas. Damages due to disaster like earthquake, landslides, avalanches, floods, flash floods, urban flooding etc. are occurring and its took a long time for real time damage assessment by remote sensing agencies which depend upon the 
weather and terrain conditions. UAS / Drones are future of disaster response, relief and recovery in future.

\section{${ }^{5}$ Disaster Stages and UAS}

${ }^{6}$ Coppola 2011; Harper 2006 elaborates and reiterates five key elements of disaster management consist of:

1. Prevention-relates to activities that will either prevent an incident occurring or minimize the impact of a potential incident;

2. Mitigation - in a similar manner to prevention, seeks to reduce the likelihood and impact of a hazard or an event on a community;

3. Preparedness - relates to activities to ensure that communities are better placed to respond to and cope with the impact of an incident;

4. Response-relates to activities that allow a community to control, respond to and reduce the impact of an incident; and

5. Recovery-relates to returning the community to a state of preparedness and to recover from the impact of an incident and move toward rehabilitation.

Majorly disaster management focus on three points i.e., pre, during and post disaster phases. The operational lifecycle for UAS participating in natural as well as manmade disaster management. The disaster management cycle comprises three stages:

$>$ Pre-disaster preparedness-UAS survey related events that come first in disaster, offer static WSN-based threshold sensing, and set up an EWS.

$>$ Disaster valuation-UAS provide situational awareness during the disaster in real time and provides comprehensive damage studies for logistical planning.

$>$ Disaster response and recovery- UAS support SAR missions, forming the communications pillars, and they provide insurance-related field surveys.

Unmanned aerial Systems (UAS) equipped with remote sensing instrumentation offer numerous opportunities in ${ }^{7}$ disaster mapping. When UAS acquire photogrammetry-ready data with appropriate imagery metadata, the capabilities of UAS for disaster research and management can be further realized. High-resolution images can be analysed and used to produce hazard maps, dense surface models (DSM), detailed building renderings, comprehensive elevation models, and other disaster area characteristics. These data can then be analysed using remote sensing methods (Camera calibration, photogrammetric techniques, and aerial triangulations) in imagery collection and analysis to produce quality digital elevation models (DEMs) or visual interpretation to coordinate further activities and verify experimental disaster modeling. The data can also be gathered before a disaster in order to map immediate pre-event conditions of critical facilities \& infrastructure, and monitor susceptible environmental concerns.

Following are some of the applications of UAS in disaster management as given:-

i. Easy and fast generation of large scale high resolution maps, images and models such as DEM / DTM of identified sites.

ii. Topographic mapping with simulated modeling of events and related processes.

iii. The monitoring of flood events, landslides and landslide dammed lakes created in inaccessible terrain and earthquake induced damage / loss. 
iv. Rapid mapping of affected areas within a short time period.

What is Unmanned Aerial System (UAS)

The UAS is an acronym for Unmanned Aerial Vehicle, which is an aircraft with no pilot on panel. UAVs can be remote controlled aircraft (e.g. flown by a pilot at a ground control station) or can fly autonomously based on pre-programmed flight plans or further complex dynamic automation systems. UAS are currently used for various missions, including exploration and outbreak roles. UAS is defined as being proficient to control, sustained level flight and powered by a jet or reciprocating engine. In addition, a cruise missile can be measured to be a UAS, but is treated separately on the basis that the vehicle is the armament. The acronym UAS has been expanded in some cases to UAVS (Unmanned Aircraft Vehicle System). Officially, the term 'Unmanned Aerial Vehicle' was changed to 'Unmanned Aircraft System' to reflect the fact that these complex systems include ground stations and other elements besides the actual air vehicles. The term UAS, however, is not widely used as the term UAV has become part of the current wordlist.

Prompt advancement in technology is enabling more and more capability to be placed on smaller airframes which is spurring a large increase in the number of UAS being deployed in crises situation. The use of UAS in combat is so new that no formal DoD wide reporting procedures have been established to track UAS flight hours. As the competences grow for all types of UAV, various nations continue to subsidize their research and development leading to further advances enabling them to perform a multitude of missions. UAV no longer only perform intelligence, surveillance, and reconnaissance (ISR) missions, although this still remains their predominant type and hence can be the most effective tool for disaster management. Their roles have expanded to areas including disaster network node or communications relay, combat search and rescue (CSAR), and derivations of these themes in worst case scenario. These UAS range in cost from a few thousand dollars to tens of millions of dollars, and the aircraft used in these systems range in size from a Micro Air Vehicle (MAV) weighing less than one pound to large aircraft weighing over 40,000 pounds.

\section{UAS Types}

1. Objective and inducement - providing ground and aerial gunnery a target that simulates an enemy aircraft or missile

2. Investigation - providing battlefield intelligence or destruction due to disaster

3. Battle - providing attack capability for high-risk missions

4. Research and development - used to further develop UAS technologies to be integrated into field deployed UAS flying machine

5. Civil and Commercial UAS - UAS specifically designed for civil and commercial applications. 


\section{Applications of UAS}

UAS is very effective in risk mapping due to its capability to reach to difficult terrains and providing quick results. Now-a-days, manufacturing and use of UAS or drones are done by many Government agencies / Universities, private agencies and various other organizations like Delhi Technological University (DTU), IIT-Kanpur, Defence Research Development Organization (DRDO), and Remote Sensing Agencies such as Indian Institute of Remote Sensing (IIRS) and National Remote Sensing Centre (NRSC) etc. Therefore it is an opportunity to utilize their efforts for disaster management purposes. This technology will be beneficial in various aspects of disaster risk reduction. It will create a capacity building and human resource development amongst concerned State Government / UT to utilize UAS for different purpose in Disaster Management for example study done after earthquake of 25thApril, 2015 in Nepal for post-disaster recovery studies by involving Kathmandu University students with the help of UAViators Humanitarian UAV Network, DJI and PIX4D.UAS have been used in many different disaster management applications, but mostly for the following:

\begin{tabular}{|l|l|}
\hline Observing, predicting, and early warning dissemination & $\begin{array}{l}\text { Using physical structure and environmental monitoring } \\
\text { and analyzing facts and figures for forecasts, UAS can } \\
\text { act as early warning systems (EWSs) }\end{array}$ \\
\hline $\begin{array}{l}\text { Emergency/Crises information amalgamation and } \\
\text { sharing }\end{array}$ & $\begin{array}{l}\text { By combining diverse sources of available information } \\
\text { or providing a channel between different information } \\
\text { technologies, UAS can support other applications during } \\
\text { crises management. }\end{array}$ \\
\hline $\begin{array}{l}\text { Conditional awareness and logistics and evacuation } \\
\text { sustenance }\end{array}$ & $\begin{array}{l}\text { UAS can help in collecting information during the } \\
\text { disaster phase, victim movement and rescue teams } \\
\text { deployment. }\end{array}$ \\
\hline Separated communication system & $\begin{array}{l}\text { UAS can re-establish the impaired or demolished } \\
\text { communication infrastructure during crises situation. }\end{array}$ \\
\hline Search and Rescue missions & $\begin{array}{l}\text { UAS can search for and rescue people lost, injured, or } \\
\text { trapped by debris. }\end{array}$ \\
\hline Damage assessment & $\begin{array}{l}\text { UAS can help evaluate the damage though different } \\
\text { approaches and procedure, such as structural health } \\
\text { monitoring and UAS video inspection. }\end{array}$ \\
\hline Media reporting & $\begin{array}{l}\text { UAS could help convey timely information to listeners } \\
\text { for informational purposes in contrast to providing } \\
\text { situational awareness for rescue teams). }\end{array}$ \\
\hline Medical submissions & $\begin{array}{l}\text { Although controlled in the means of payload weight, } \\
\text { specialized UAS could automatically deliver supplies } \\
\text { necessary to keeping people alive, even in the case of a } \\
\text { destroyed transport infrastructure with cut-off roads }\end{array}$ \\
\hline Infrastructure rebuilding & $\begin{array}{l}\text { Utilizing networks of UAS could speed up the process of } \\
\text { inspections } \\
\text { the efficiency and precision of infrastructure } \\
\text { reconstruction }\end{array}$ \\
\hline
\end{tabular}

\section{Approach of UAS in handling disaster scenario in India}




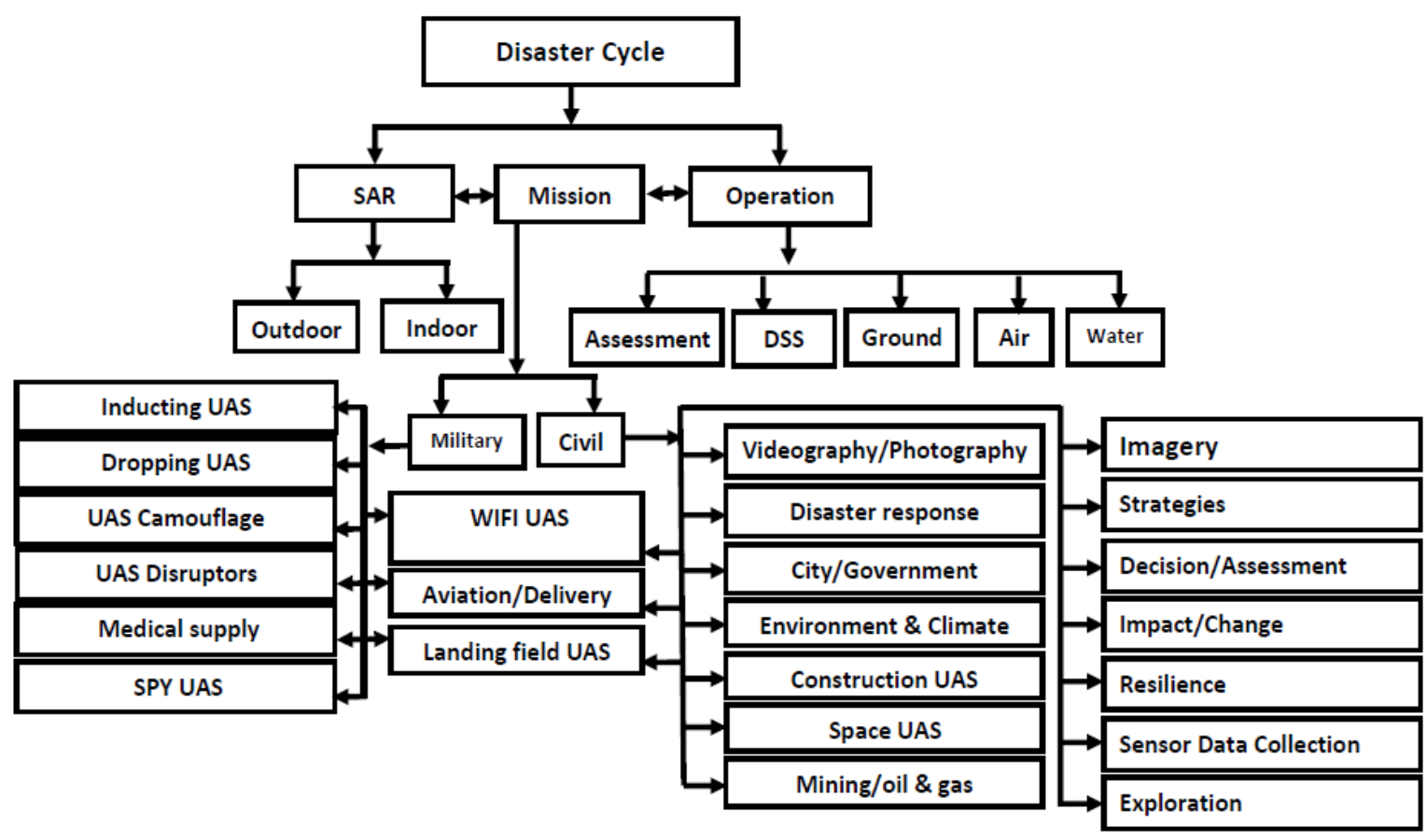

The above figure elaborates the approach that UAS follows and provide necessary information for proper decision making in disaster management. Search \& rescue (SAR), mission, operations can be very well organized and coordinated with the help of UAS. The applicability of UAS in both military and civil domain makes the technology robust and acceptable for each and every segment of decision making. The complete mechanism of UAS in disaster cycle is to assist the operations at EOC and to coordinate, mobilize resources effectively.

\section{Conclusion}

The current state and diversity of research provides considerable evidence to support the strategic investment in UAS technology to develop new and enhance existing operational capabilities for disaster management. The appendix provides a mission matrix which can be used as a guide to further research potential disaster management roles for UAS. This study demonstrates that UAS can be used across all phases of disaster management for both generic and specific tasks; however, the technical capabilities of UAVs exceed the permissible use this technology. Decision makers and agencies will have to work closely with national regulators of UAS to ensure that UAS-based operations are safe and do not endanger other aircraft. Similarly, officials will need to address community concerns and build in safeguards to protect against any breaches of privacy and individual rights whilst developing UAS-based concepts of operations of disaster management. When developing these concepts, it is essential that decision makers/stakeholders understand that UAS operations are a balancing act across a wide range of 
variables and they need to integrate into a complex operational environment of disaster management.

\begin{tabular}{|l|l|}
\hline Disaster Management Applications & 1. Monitoring natural disasters \\
& 2. Communication relays \\
& 3. Monitoring landslides \\
& 4. Searching for missing persons \\
& 5. Fire scene examination \\
& 6. Monitoring floods \\
& 7. Post disaster inspection and relief \\
& 8. Infrastructure inspection \\
\hline Disaster Unmanned Aerial Systems & 1. Traffic surveillance and many more \\
\hline & 2. Lata Collection \\
& 3. GIS mapping \\
& 4. FLIR thermal camera imaging \\
& 5. Aerial surveys \\
& 6. Sonar pulse \\
& 7. Image sensors \\
\hline
\end{tabular}

\section{$\underline{\text { References }}$}

1. National Strategy for Chemical, Biological, Radiological, Nuclear, and Explosives (CBRNE) Standards

2. Unmanned aerial systems for photogrammetry and remote sensing: A review I.ColominaP.Molina

3. Sendai Framework for Disaster Risk Reduction 2015-2030 (Sendai Framework)

4. Incident Response System, National disaster Management Authority, GOI

5. www.unisdr.org/2005/mdgs-drr/national-reports/India-report.pdf

6. Introduction to homeland security: Principles of all-hazards risk management J Bullock, G Haddow, DP Coppola - 2011 - books.google.com

7. National Database for Emergency Management, NRSC, ISRO

8. Drone application for supporting disaster management : Agoston Restos

9. Mapping a Volcano Hazard Area of Mount Sinabung Using Drone: Preliminary Results : A P M Tarigan ,D Suwardhi ,M N Fajri ,F Fahmi

10. Blyenburgh, P. (Edit. 2009/2010) UAS Yearbook, UAS - The Global Perspective, Paris, France. Molnar, A. (2014) UAV alkalmazások fejlesztése az Óbudai Egyetemen (Development of UAV Applications at Óbuda University), Presentation, AROP Project Conference, Szolnok, Hungary, 28. February 2014.

11. Schweier, C. and Markus, M. (2006) Classification of Collapsed Buildings for Fast Damage and Loss Assessment. Bulletin of Earthquake Engineering, 4, 177-192. http://dx.doi.org/10.1007/s10518-006-9005-2

12. Restas, A. (2012) Unmanned Aircraft System Applications: Firefighting. Introduction to Unmanned Systems: Air, Ground, See \& Space. In: LeMieux, J., Ed., Technologies and Commercial Applications, LCCN 2012954516.

13. Rehor, M. (2007) Classification of Building Damage Based on Laser Scanning Data. The Photogrammetric Journal of Finland, 20, 54-63. http://foto.hut.fi/seura/julkaisut/pjf/pjf_e/pjf_e.html

14. Restas, A. (2015) Thematic Division and Tactical Analysis of the UAS Application Supporting Forest fire Manage-ment. In: Viegas, X.D., Ed., Advances in Forest Fire Research, Coimbra, Portugal. http://dx.doi.org/10.14195/978-989-26-0884-6_172

15. Restas, A. (2011) UAS Applications: From Aerial Patrol to Prescribed Fires. Wildfire 2011, The 5th International Wildland Fire Conference, Sun City, South Africa, 9-13 May 2011.

16. www.theuav.com 